\title{
Dampak Implementasi Sistem Informasi Manajemen Pendidikan pada Kegiatan Akademik di Sekolah
}

\section{The Impact of the Implementation of Education Management Information Systems on Academic Activities in Schools}

\author{
Widia Murni Wijaya ${ }^{1, *}$, dan Decky Risdiansyah ${ }^{2}$ \\ ${ }^{1}$ Universitas Negeri Yogyakarta, Yogyakarta, D. I. Yogyakarta, Indonesia \\ ${ }^{2}$ Universitas Pendidikan Indonesia, Bandung, Jawa Barat, Indonesia \\ widiamw@uny.ac.id*
}

Naskah diterima tanggal 20/01/2020, direvisi akhir tanggal 11/04/2020, disetujui tanggal 28/04/2020

\begin{abstract}
Abstrak
Penelitian ini bertujuan untuk mendeskripsikan tentang pemanfaatan sistem informasi manajemen pendidikan dalam pengelolaan kegiatan akademik, dan pemenuhan kebutuhan sistem (hardware dan software) dan kebutuhan pengguna (brainware) dalam mendukung pemanfaatan sistem informasi manajemen pendidikan di sekolah. Metode kualitatif dipilih untuk menggambarkan fakta yang ada dengan menggunakan teknik observasi, wawancara, dan dokumentasi. Penelitian dilaksanakan di enam sekolah negeri dengan sebaran tiga sekolah menengah atas (SMA) dan tiga sekolah menengah kejuruan (SMK). Adapun informan dalam penelitian ini meliputi enam tenaga kependidikan dan enam guru. Hasil penelitian menunjukkan bahwa enam sekolah yang diteliti telah menggunakan sistem informasi akademik sebagai pemanfaatan sistem informasi manajemen pendidikan untuk mengelola kegiatan akademik dan memudahkan pengambilan keputusan di tingkat manajemen sekolah, dan kebutuhan sistem (hardware dan software) sudah disesuaikan dengan mengikuti perkembangan hardware dan software serta kebutuhan pengguna (brainware) dikelola dengan baik dengan memberikan pelatihan secara berkala untuk meningkatkan kemampuan para guru.
\end{abstract}

Kata kunci: Akademik, Sistem Informasi, Sistem Informasi Manajemen.

\begin{abstract}
This study aims to describe the utilization of education management information systems in the management of academic activities, and the fulfillment of system requirements (hardware and software) and user needs (brainware) in supporting the utilization of education management information systems in schools. The qualitative method was chosen to describe existing facts using observation, interview, and documentation techniques. The study was conducted in six public schools, namely three senior high schools and three vocational high schools. The informants in this study are six educational staff and six teachers. The results showed that schools have been using academic information systems as the utilization of education management information systems to manage academic activities and facilitate decision making at the school management level, and system requirements (hardware and software) have been adjusted to follow the trend of hardware and software, and user needs (brainware) have been well managed by providing regular training to improve the ability of teachers.
\end{abstract}

Keywords: Academic, Information Systems, Management Information Systems. 


\section{PENDAHULUAN}

Sebuah lembaga pendidikan memiliki beragam kebutuhan untuk mendukung jalannya kegiatan manajemen lembaga tersebut. Salah satu kebutuhan manajemen pendidikan saat ini berupa penyediaan akses data dan informasi yang diperoleh dari proses menghimpun, mendata, mengolah, menggandakan, menyimpan, dan mengirim (Yakub \& Hisbanarto, 2014). Kegiatan tersebut apabila dilakukan dengan cara manualpastiakankurangefektif, sebagaimana kecenderungan perubahan perilaku manusia sekarang yang menginginkan proses serba cepat dan mudah (Leonardi, 2011).

Pada umumnya fungsi manajemen pendidikan terdiri dari planning, organizing, actuating, dan controlling (Terry, 1977; Bush, 2010) yang memiliki delapan bidang garapan inti, mulai dari kurikulum, fasilitas, peserta didik, personalia, pembiayaan, tata usaha, organisasi, dan hubungan dengan masyarakat (Budiwibowo \& Sudarmiani, 2019). Dari sekian banyak pekerjaan tersebut, para pengelola pendidikan tentu membutuhkan sistem informasi manajemen (SIM) untuk meringkas pekerjaan mereka serta mengintegrasikan data dan informasi yang dibutuhkan.

Sistem informasi manajemen hadir dalam balutan kecanggihan teknologi untuk menawarkan jawaban dari permasalahan yang ada. SIM sendiri mengatur tentang pemanfaatan sumber daya manusia, teknologi, prosedur, dan data yang berfungsi untuk menghasilkan informasi bagi suatu lembaga atau organisasi (Oz, 2009; Mutch, 2010; Alcamí \& Carañana, 2012). Adapun peran SIM dalam kegiatan pendidikan dapat menjadi suatu sistem yang dapat diandalkan dalam kegiatan manajemen untuk membuat keputusan-keputusan manajemen, baik yang berupa keputusan pada kegiatan yang bersifat teratur maupun keputusan strategik (Turban \& Volonino, 2011; Wijaya, 2016). Hal ini juga diperkuat dengan keuntungan yang dihadirkan oleh SIM yang dapat mengurangi biaya operasional, mengurangi kesalahan dan meningkatkan performa kerja (Stair \& Reynolds, 2016; Laudon \& Laudon, 2019).
Mengingat peran SIM yang begitu penting, maka pengelolaan SIM pendidikan sangat diperlukan oleh lembaga pendidikan sekarang ini, dengan melihat bahwa penggunaan dan pengelolaan sistem informasi manajemen pendidikan tidak bisa dilepaskan dari kegiatan pendidikan itu sendiri (Rochaety, 2017). Dengan begitu, SIM pendidikan diharapkan dapat mengatur dan merencanakan kegiatan lembaga pendidikan misalnya sekolah, dengan baik dan sesuai dengan visi, misi, dan tujuan sekolah tersebut sehingga menciptakan pendidikan yang bermutu.

Pemanfaatan SIM pendidikan di sekolah diantaranya dapat meningkatkan akses informasi sekolah, meningkatkan efesiensikegiatansekolah,sertameningkatkan kualitas sekolah (Prasojo, 2013). Hal ini diperkuat bahwa SIM pendidikan juga berpotensi digunakan dalam pengelolaan kegiatan akademik untuk menciptakan akses kecepatan, akurasi, dan pendataan yang terintegrasi, sehingga layanan akademik akan berjalan dengan efektif dan efisien, misalnya pengembangan sistem informasi akademik (Hidayat, 2009; Wijaya, 2016). Sistem informasi akademik secara khusus dikembangkan untuk memenuhi kebutuhan sekolah, dimana sekolah menghendaki pengelolaan kegiatan akademik yang terkomputerisasi sebagai kontribusi untuk meningkatkan kualitas pelayanan sekolah.

Persoalan pokok mengenai pemanfaatan SIM pendidikan bagi suatu sekolah yakni bagaimana menerapkan SIM pendidikan sekaligus memanfaatkannya untuk kepentingan sekolah, dalam bentuk pengelolaan kegiatan akademik yang terintegrasi dalam suatu jaringan (Lipursari, 2013; Wahyudi et al., 2015; Merindasari et al., 2015; Susanti, 2016; Hermawan et al., 2016). Mencermati berbagai fenomena dari perkembangan SIM pendidikan serta pemanfaatannya di sekolah saat ini, maka seharusnya stakeholder sekolah mengantisipasi perkembangan SIM pendidikan serta pemanfaatannya sebagai upaya mendukung efektifitas dan efisiensi suatu kegiatan. Pemanfaatan SIM pendidikan 
juga harus diimbangi dengan peningkatan sumber daya manusia (brainware) sebagai pengguna sistem (Sidh, 2013) dalam proses pendidikan karena sumber daya manusia merupakan komponen penunjang yang dibutuhkan untuk menjalankan SIM pendidikan. Selain itu diperlukan dukungan perangkat keras (hardware) dan perangkat lunak (software) sebagai komponen utama SIM pendidikan (Brown et al., 2012).

Dua pertanyaan penelitian yang menjadi dasar penelitian ini:

1. Bagaimana pemanfaatan sistem informasi manajemen pendidikan dalam pengelolaan kegiatan akademik termasuk manfaat dan kendala yang muncul?

2. Bagaimana kebutuhan sistem (hardware dan software) dan kebutuhan pengguna (brainware) dalam mendukung pemanfaatan sistem informasi manajemen pendidikan?

Dengan demikian, penelitian ini bertujuan untuk mengulas lebih dalam mengenai dampak sistem informasi manajemen pendidikan terutama dalam pengelolaan kegiatan akademik di sekolah.

\section{METODE PENELITIAN}

Untuk menemukan jawaban penelitian sebagaimana yang dinyatakan dalam pertanyaan penelitian, maka penelitian ini menggunakan metode penelitian kualitatif yakni proses pencatatan yang menggambarkan fakta yang ada berdasarkan keadaan objek yang diteliti (Creswell, 2018). Metode ini bersifat interpretive yang cirinya berdasarkan adanya pendapat karena hasil penelitian lebih berkaitan dengan interpretasi data yang ditemukan di lapangan (Sugiyono, 2019).

Penelitian dilaksanakan di enam sekolah negeri di provinsi Daerah Ibukota Yogyakarta dengan sebaran tiga sekolah menengah atas (SMA) dan tiga sekolah menengah kejuruan (SMK). Pemilihan enam sekolah ini didasarkan pada pertimbangan kelayakan objek untuk mendapatkan data dan informasi sebagai penunjang tercapainya tujuan penelitian. Durasi penelitian ini dilakukan selama 4 bulan, durasi ini termasuk penyusunan literatur, pemahaman terhadap objek penelitian, wawancara, serta analisis data untuk menginterpretasikan data.

Dalam penelitian ini, teknik pengumpulan data menggunakan pangambilan sampel purposive yakni pengambilan sampel berdasarkan kriteria tertentu (Sugiyono, 2019) melalui observasi, wawancara, dan dokumentasi yang dilakukan dengan para informan penelitian secara langsung tanpa dipengaruhi unsur-unsur lain dari luar lingkungan. Adapun objek dalam penelitian ini berasal dari enam sekolah yang meliputi tenaga kependidikan pengelola sistem informasi akademik sebanyak enam orang dan pengguna sistem informasi akademik yakni guru sebanyak enam orang. Maka dari itu, peneliti berhubungan langsung dengan situasi dan sumber data yang diteliti.

Selanjutnya sumber data yang dikumpulkan diklasifikasikan menjadi data primer dan data sekunder. Data primer bersumber dari observasi dan wawancara yang dilakukan terhadap objek penelitian. Sedangkan data sekunder dikumpulkan dari berbagai dokumen yang berhubungan dengan subjek penelitian dan mendukung data primer.

Teknik analisis data dalam penelitian ini menggunakan analisis deskriptif kualitatif yang ditujukan untuk mengumpulkan informasi secara nyata dan terperinci; mengidentifikasi masalah; membuat perbandingan atau evaluasi, dan menentukan apa yang harus dilakukan dalam menghadapi masalah dan belajar dari pengalaman keadaan sebelumnya untuk menetapkan rencana dan keputusan di masa yang akan datang (Miles et al., 2018).

\section{HASIL}

\subsection{Pemanfaatan sistem informasi manajemen pendidikan}

Berdasarkan hasil observasi dan wawancara yang dilakukan dengan para tenaga kependidikan pengelola sistem sekolah dan para guru didapatkan bahwa semua sekolah yang diteliti telah menggunakan sistem informasi akademik sebagai pemanfaatan sistem informasi manajemen pendidikan. Terdapat dua sekolah 
yang mengembangkan sistem informasi akademik sendiri dan empat sekolah lainnya menggunakan sistem informasi akademik yang dikembangkan oleh pemerintah. Adapun dua sekolah yang mengembangkan sistem informasi akademik sendiri merupakan sekolah menengah kejuruan (SMK) yang memiliki jurusan komputer sehingga sekolah ini mampu mengembangkan sistem informasi akademik dengan memanfaatkan teknologi yang ada. Guru yang juga salah satu pengembang sistem informasi akademik sendiri berkata:

"Sekolah mengembangkan sistem informasi akademik sesuai dengan instruksi kepala sekolah dan sumber daya di sekolah juga mendukung untuk mengembangkan sistem ini."

Sebelum adanya sistem informasi akademik, enam sekolah yang diteliti menggunakan aplikasi pengolah kata dan data untuk membantu pengelolaan kegiatan akademik di sekolah, hal ini tidak optimal terutama sering terjadi kesalahan input nilai yang dilakukan oleh guru sehingga berakibat pada nilai akhir siswa dan jika file terhapus maka harus mengulang kembali dari awal. Kemudian sistem informasi akademik ini muncul untuk mempermudah layanan akademik. Adapun manfaat dari adanya sistem informasi akademik ini untuk memberi kemudahan dalam mengelola kegiatan akademik dan memudahkan guru dalam mengambil keputusan terkait nilai akademik siswa. Ini diperkuat dengan hasil wawancara yang dilakukan dengan guru, guruberkata:

"Merasa sangat terbantu karena memudahkan pekerjaan dalam hal mengelola nilai siswa."

Selain itu, hasil wawancara dengan tenaga kependidikan pengelola sistem dari sekolah yang berbeda merasa terbantu dalam memberikan layanan akademik terutama pada siswa, ia berkata:

"Contoh keuntungannya, saat siswa datang meminta daftar nilai dan rangking, tidak perlu menunggu lama tidak sampai berganti hari."

Alur sistem informasi akademik baik yang dikembangkan sendiri oleh sekolah maupun yang dikembangkan oleh pemerintah di enam sekolah yang diteliti memiliki alur sistem yang sama dan berfokus pada pengelolaan nilai siswa, dimana pengguna harus memiliki akun atau terdaftar pada sistem terlebih dahulu, kemudian pengguna dapat mengakses sistem.

Pengguna yang dapat mengakses sistem informasi akademik meliputi admin, kepala sekolah, guru, staff, dan siswa. Sedangkan tugas masing-masing dari pengguna yakni admin bertugas sebagai pengelola sistem informasi akademik tersebut apabila terjadi hambatan dan melakukan perbaikan sistem, kepala sekolah bertugas sebagai pengawas, guru bertugas sebagai pengolah nilai siswa, sedangkan siswa sebagai penerima nilai. Sistem tersebut memuat data yang meliputi data siswa, data guru, data mata pelajaran, serta datanilai akademik siswa.

\subsection{Kebutuhan sistem dan kebutuhan pengguna}

Kebutuhan sistem, dalam hal ini perangkat keras (hardware) dan perangkat lunak (software) menjadi pendukung utama untuk menjalankan sistem informasi akademik di sekolah. Adapun kebutuhan hardware yang digunakan sekolah dalam mendukung sistem informasi akademik diantaranya komputer/ laptop, keyboard, mouse, printer, wireless access point dan router.

Sedangkan kebutuhan software yang digunakan sekolah dalam mengakses sistem informasi akademik yakni operating system, browser dan aplikasi yang dikembangkan pemerintah, namun untuk sekolah yang mengembangkan sistem informasi sendiri, ada tambahan kebutuhan software seperti pemilihan bahasa pemrograman dan aplikasi penyuntingnya, aplikasi editor foto/gambar dan pembuatan efek, dan aplikasidatabase.

Adapun manusia sebagai brainware menjadi pendukung yang tidak bisa dilepaskan dari sistem informasi akademik sekolah sebab manusia sebagai pengguna yang akan mengoperasikan sistem tersebut. Berdasarkan hasil wawancara, untuk kebutuhan pengguna sistem maka pihak sekolah senantiasa menyelenggarakan pelatihan agar para pengguna mampu menggunakan sistem yang dikembangkan oleh sekolah karena pengguna yang melek akan komputer dan pendukung lainnya dapat memahami dan mengakses sistem 
yang ada. Peserta pelatihan yang diadakan sekolah diantaranya kepala sekolah, guru, dan staff. Pelatihan berbasis komputer dilakukan sekolah paling sedikit satu kali dalam setahun. Hal ini diperkuat dengan pernyataan tenaga kependidikan pengelola sistem yang juga sebagai instruktur pelatihan para guru, iaberkata:

"Iya, pelatihan dilaksanakan satu kali setahun untuk guru baru dan juga guru yang ingin meningkatkan kemampuan komputernya."

Namun hal yang terjadi di lapangantidak sepenuhnya berjalan lancar, beberapa hambatan hadir dalam pelatihan yang diselenggarakan sebagai pemenuhan kebutuhan pengguna sistem, dimana pelatihan sebagai program sekolah ini berbenturan dengan guru yang tidak mau mengerti komputer. Guru yang seperti ini didapati rata-rata guru yang sudah tua dan kalau pun mereka mengikuti pelatihan terkadang kemampuannya tertinggal dari gurulain.

\section{PEMBAHASAN}

Sistem informasi manajemen (SIM) sekarang ini menjadi suatu sistem yang dibutuhkan suatu lembaga pendidikan untuk menghasilkan informasi yang terpercaya dalam memenuhi kebutuhan pada semua tingkatan manajemen serta untuk mendukung pengambilan keputusan (Susanto, 2017; Laudon \& Laudon, 2019). Sistem informasi manajemen pendidikan memiliki peranan penting di sekolah karena sangat mempengaruhi terhadap cepatnya informasi yang dihasilkan dan menawarkan kemudahan dalam kegiatan manajemen sekolah (Lipursari, 2013; Mingers \& Willcocks, 2014).

Sebagaimana enam sekolah yang diteliti sudah menerapkan penggunaan sistem informasi akademik sebagai wujud pemanfaatan SIM pendidikan. Diantara enam sekolah tersebut, dua sekolah memutuskan untuk mengembangkan sistem informasi akademik sendiri yang disesuaikan dengan kebutuhan dan masalah yang terjadi pada sekolah, sebab apabila sekolah menggunakan sistem informasi akademik yang disediakan oleh pemerintah, ada kebutuhan sekolah yang tidak termasuk di dalam fitur sistem tersebut.

Dua sekolah yang mampu mengembangkan sistem informasi akademik sendiri merupakan sekolah menegah kejuruan (SMK) yang memiliki jurusan komputer di sekolah sehingga ada sumber daya di sana untuk mengembangkan sistem sendiri. Sistem informasi akademik ini diterapkan untuk memberikan layanan akademik yang cepat dan akurat serta membantu guru dan siswa dalam memperoleh informasi yang berkaitan dengan nilai (Triwiyono \& Meirawan, 2013; Susanti, 2016). Dengan demikian, sistem informasi akademik merupakan suatu cara untuk mempermudah dalam mengolah data menjadi informasi dan menyebarkan informasi tersebut untuk mencapai tujuan sekolah (Wahyudi et al., 2015; Merindasari et al., 2015).

Penggunaan sistem informasi akademik diatur kebijakannya oleh sekolah dan menugaskan tenaga kependidikan untuk mengelola sistem yang digunakan sekolah tersebut. Adapun sistem informasi akademik yang digunakan oleh semua sekolah merupakan sistem informasi yang berbasis web, dimana pengguna perlu memiliki fasilitas username dan password untuk mengakses sistem informasi akademik tersebut. Dengan begitu, sistem informasi berbasis web menjadi pilihan favorit yang dikembangkan oleh sekolah untuk memfasilitasi agar pengguna dapat menjangkau sistem kapan saja dan dimana saja (Heijden, 2009; Herliana \& Rasyid, 2016; Hermawan et al., 2016).

Selain itu, sistem informasi akademik ini juga mengintegrasikan semua data yang dimasukkan kedalam sistem oleh pengguna, hal ini akan mempermudah untuk mengelola data menjadi informasi yang berkaitan dengan nilai siswa. Dalam sistem informasi akademik terdapat data-data yang dikelola didalamnya, data-data tersebut dilindungi dengan keamanan yang ada pada sistem informasi akademik tersebut sehingga meminimalisir adanya kehilangan data, yang pada akhirnya data-data tersebut menjadi informasi yang dapat digunakan oleh guru dalam pengambilan keputusan mengenai nilai akademik siswa. Hal ini sejalan dengan fungsi sistem informasi manajemen untuk mendukung setiap tingkatan pada proses pengambilan keputusan yang berkaitan dengan situasi yang ada (O'Brien \& Marakas, 2011; Cecez-Kecmanovic et al., 2014; Baltzan, 2018). Pemanfaatan SIM pendidikan merupakan perpaduan antara beberapa komponen yakni 
sumber daya manusia dan teknologi (hardware dan software) untuk mengolah data dalam rangka mendukung kegiatan manajemen dalam bidang pendidikan (Prasojo, 2013; Rochaety, 2017). Adapun komponen perangkat keras (hardware) pada sekolah-sekolah yang diteliti, dapat dikatakan bahwa komponen hardware yang tersedia di sekolah sudah sesuai kebutuhan sistem untuk mendukung penerapan sistem informasi akademik, hal ini dilihat dari hasil pengamatan yang dilakukan dengan mendata hardware yang tersedia di sekolah dan memastikan hardware tersebut dapatberfungsi.

Sedangkan kebutuhan perangkat lunak (software) untuk menunjang berjalannya sistem informasi akademik pun sudah berfungsi dengan lancar, baik sistem yang dikembangkan oleh pemerintah atau sistem yang dikembangkan oleh sekolah sendiri. Namun pengembangan sistem informasi akademik yang digunakan oleh setiap sekolah yang juga termasuk komponen software masih sebatas memuat data penilaian siswa saja padahal masih banyak fitur-fitur lain yang dapat dikembangkan berkaitan dengan kegiatan akademik. Hal ini perlu menjadi perhatian para pengembang untuk menambahkan fitur-fitur baru untuk mengoptimalkan sistem informasi akademik yang dikembangkan.

Untuk kebutuhan pengguna sistem (brainware), berdasarkan hasil penelitian didapatkan bahwa semua sekolah telah dan rutin mengadakan pelatihan untuk meningkatkan keterampilan para guru dalam menggunakan komputer dan sistem informasi akademik yang digunakan di sekolah, paling sedikit satu kali dalam setahun. Semua guru diikutsertakan dalam pelatihan ini tanpa terkecuali. Pelatihan yang diadakan oleh sekolah biasanya dilakukan secara bertahap dengan jenjang yang semakin meningkat.

Adapun hambatan yang didapatkan selama pelatihan diadakan yakni terdapat beberapa guru terutama guru-guru yang sudah tua tidak termotivasi untukmeningkatkan kemampuannya. Biasanya guru ini hanya mengerti program pengolah kata saja dan tidak mau belajar yang lain. Solusi untuk mengatasi hambatan tersebut dapat dengan cara memisahkan dan membuat kelas tersendiri untuk guru-guru yang sudah tua, hal ini dilakukan untuk memberikan perlakuan yang berbeda dengan menyesuaikan kemampuan guru-guru tersebut. Sebagaimana diketahui bahwa peran guru sebagai pengguna sistem dibutuhkan sebagai penunjang dalam penerapan sistem informasi yang digunakan oleh sekolah (Sidh, 2013; Agustiandra, \& Sabandi, 2019).

\section{KESIMPULAN}

Pilihan menerapkan sistem informasi akademik di sekolah sebagai pemanfaatan sistem informasi manajemen pendidikan menjadi pilihan yang sudah tepat, melihat bahwa kegiatan akademik merupakan kegiatan yang rutin dilakukan sehingga perlu adanya penerapan sistem informasi disana agar data terkomputerisasi dengan baik dan dapat memberikan layanan akademik yang optimal untuk para penggunanya. Selain itu, informasi yang dihasilkan dapat dijadikan sebagai landasan dalam pengambilan keputusan di tingkat manajemen sekolah. Adapun pemenuhan kebutuhan sistem (hardware dan software) dilakukan untuk mendukung penerapan dan kelancaran penggunaan sistem informasi akademik. Maka dari itu, sekolah melakukan peningkatan secara periodik agar kebutuhan sistem sekolah mengikuti tren hardware dan software. Sedangkan kebutuhan pengguna (brainware) diperhatikan dengan baik oleh sekolah melalui pelatihan yang diadakan oleh sekolah sebagai upaya meningkatkan kemampuan pengguna sistem terutama guru dalam menggunakan komputer dan sistem informasi akademik sekolah.

\section{DAFTAR RUJUKAN}

Agustiandra, V., \& Sabandi, A. (2019). Persepsi Guru Terhadap Penerapan Sistem Informasi Manajemen di Sekolah Menengah Kejuruan (SMK) Negeri 3 Padang. Jurnal Bahana Manajemen Pendidikan, 8(1), 18.

Alcamí, R. L., \& Carañana, C. D. (2012). Introduction to Management Information Systems. Castelló de la Plana: Servei de Comunicació i Publicacions.

Baltzan, P. (2018). Information Systems. New York: McGraw-Hill.

Brown, C. V., DeHayes, D. W., Hoffer, J. A., Martin, E. W., \& Perkins, W. C. (2012). Managing Information 
Technology. New Jersey: Pearson.

Budiwibowo, S., \& Sudarmiani. (2019). Manajemen Pendidikan. Yogyakarta: Andi.

Bush, T. (2010). Theories of Educational Leadership and Management. Thousand Oaks, CA: SAGE Publication.

Cecez-Kecmanovic, D., Galliers, R. D., Henfridsson, O., Newell, S., \& Vidgen, R. (2014). The sociomateriality of information systems: Current status, future directions. MIS Quarterly, 38(3), 809-830.

Creswell, J. W. (2018). Research Design: Qualitative, Quantitative, and Mixed Methods Approaches. Thousand Oaks, CA: SAGE Publication.

Heijden, H. V. D. (2009). Designing Management Information Systems. New York: Oxford University Press Inc.

Herliana, A., \& Rasyid, M. R. (2016). Sistem Informasi Monitoring Pengembangan Software Pada Tahap Development Berbasis Web. Jurnal Informatika, 3(1), 41-50.

Hermawan, R., Hidayat, A., \& Gayuh, V. U. (2016). Sistem Informasi Penjadwalan Kegiatan Belajar Mengajar Berbasis Web. Jurnal Evolusi, 4(1), 72-79.

Hidayat, R. (2009). Penerapan Sistem Informasi Manajemen Sebagai Alat Pelaksanaan Sistem Administrasi Akademik. Jurnal Ilmiah Pendidikan Tinggi, 2(2), 56-59.

Laudon, K. C., \& Laudon, J. P. (2019). Management Information Systems: Managing the Digital Firm. London: Pearson.

Leonardi, P. M. (2011). When flexible routines meet flexible technologies: Affordance, constraint, and the imbrication of human and material agencies. MIS Quarterly, 35(1), 147-167.

Lipursari, A. (2013). Peran sistem informasi manajemen (SIM) dalam pengambilan keputusan. Jurnal STIE Semarang, 5(1), 26-37.

Merindasari, E., Widyaningtyas, T., \& Arifin, M. Z. (2015). Sistem Informasi Penilaian Akademik Siswa Kurikulum 2013 Berbasis Web di SMAN 1 Trenggalek. In: Seminar Nasional Sistem Informasi Indonesia (SESINDO).

Miles, M. B., Huberman, A. M., \& Saldana, J. (2018). Qualitative Data Analysis: A Methods Sourcebook. Thousand Oaks, CA: SAGE Publication.

Mingers, J., \& Willcocks, L. (2014). An integrative semiotic framework for information systems: The social, personal and material worlds. Information and Organization, 24(1), 48-70.

Mutch, A. (2010). Technology, organization, and structure-A morphogenetic approach. Organization Science, 21(2), 507-520.

O’Brien, J. A., \& Marakas, G. M. (2011). Management Information Systems. New York: McGraw-Hill.

Oz, E. (2009). Management Information Systems. Boston: Thomson.

Prasojo, L. D. (2013). Sistem informasi manajemen pendidikan. Yogyakarta: UNY Press.

Rochaety, E. (2017). Sistem informasi manajemen. Bogor: Mitra Wacana Media.

Sidh, R. (2013). Peranan Brainware dalam Sistem Informasi Manajemen. Jurnal Computech \& Bisnis, 7(1), 1929.

Stair, R. M., \& Reynolds. G. W. (2016). Fundamentals of Information Systems. Boston: Cengage Learning.

Sugiyono. (2019). Metode Penelitian Kuantitatif Kualitatif dan $R \& D$. Alfabeta. Bandung.

Susanti, M. (2016). Perancangan Sistem Informasi Akademik Berbasis Web Pada SMK Pasar Minggu Jakarta. Jurnal informatika, 3(1).

Susanto, A. (2017). Sistem Informasi Manajemen Konsep dan Pengembangan Secara Terpadu. Bandung: Linggajaya.

Terry, G. R. (1977). Principles of Management. Madison: R. D. Irwin.

Triwiyono, D. A., \& Meirawan, D. (2013). Implementasi Sistem Informasi Manajemen Akademik Berbasis Teknologi Informasi di Sekolah Dasar. Jurnal Administrasi Pendidikan, 17(1).

Turban, E., \& Volonino, L. (2011). Information Technology for Management: Improving Strategic and Operational Performance. Hoboken: Wiley.

Wahyudi, A., Sowiyah, S., \& Ambarita, A. (2015). Implementasi Sistem Informasi Manajemen Akademik Berbasis Web. Jurnal Manajemen Mutu Pendidikan, 3(1).

Wijaya, W. M. (2016). Strategic Information System Planning: Information Systems Required in Vocational School Models. In: The 6th International Conference on Educational, Management, Administration and Leadership, Bandung, Indonesia, 28 August 2016. Paris: Atlantis Press.

Yakub., \& Hisbanarto, V. (2014). Sistem Informasi Manajemen Pendidikan. Yogyakarta: Graha Ilmu. 